\title{
Evolution of the Physical, Mechanical and Electrical Properties of SiC-Reinforced Al 6061 Composites Prepared by Stir Cast Method
}

\author{
Mohammed A. Taha ${ }^{1(\mathbb{C})}$, Rasha A. Youness ${ }^{2(\mathbb{D})}$, Medhat A. Ibrahim 2,* (D) \\ 1 Solid State Physics Department, National Research Centre, El Buhouth St., 12622 Dokki, Giza, Egypt; \\ mtahanrc@gmail.com (M.A.T.); \\ 2 Spectroscopy Department, National Research Centre, El Buhouth St., 12622 Dokki, Giza, Egypt; rhakamnrc@ gmail.com \\ (R.A.Y.); medahmed6@yahoo.com (M.A.I.); \\ * Correspondence: medahmed6@yahoo.com;
}

Received: 22.07.2020; Revised: 23.08.2020; Accepted: 26.08.2020; Published: 30.08.2020

\begin{abstract}
Metal matrix composites show attractive physical properties which strongly dedicated to achieving enhanced mechanical properties. So that, the A16061 alloy matrix composites were synthesized by different weight percentages, up to $4 \mathrm{wt} . \%$, of SiC reinforced nanoparticles prepared by stir cast process. The mechanical properties, including microhardness and tensile properties like ultimate strength, yield strength, ductility, and strengthening efficiency, were evaluated. Moreover, longitudinal velocity, shear velocity, elastic, Young's, shear and bulk moduli, and Poisson's ratio were measured by ultrasonic nondestructive technique. Furthermore, the relative density, apparent porosity, and electrical conductivity are also measured. The results showed remarkable improvements in the mechanical properties of all examined alloys by adding $\mathrm{SiC}$ nanoparticles. The microhardness, ultimate strength, Young's modulus of the composites containing 4 wt.\% SiC increased to 945.2 MPa, 246.6 $\mathrm{MPa}$, and $97.3 \mathrm{GPa}$, respectively, while the ductility decreased to $20.8 \%$ compared to un-reinforced $\mathrm{Al}$ alloy. Furthermore, the bulk density and the apparent porosity increased with increasing SiC contents, while the conductivity decreased.
\end{abstract}

Keywords: A16061 matrix composites; Mechanical properties; Electrical properties; Stir cast method.

(C) 2020 by the authors. This article is an open-access article distributed under the terms and conditions of the Creative Commons Attribution (CC BY) license (https://creativecommons.org/licenses/by/4.0/).

\section{Introduction}

A composite can be defined as a combination of two or more materials, which leads to better properties than those of the individual components used alone. It is worth noting that the two constituents are called "reinforcement and matrix". In comparison with bulk materials, composite materials possess attractive properties like high strength, high stiffness, and low density, and therefore composites are highly favorable in different industries [1-4] and biomedical applications [5-8]. Aluminum and its alloys are the most commonly used metallic matrices for producing metal matrix composites [9]. In this sense, it is stated that A16061 alloy matrix composites reinforced with silicon carbide $(\mathrm{SiC})$ nanoparticles are characterized by low density, microhardness, high ultimate strength, high elastic modulus, high wear rate, and good corrosion resistance. Therefore, aluminum (Al) matrix composites are highly demanded in various industrial applications [2,3]. Such applications include aerospace, thermal management areas, industrial products, automotive applications such as engine piston, brake disc, etc., based on the unique properties of such aluminum matrix composites [11-12]. 
Noteworthy, composites-based on metals can be synthesized using different techniques such as mechanical alloying [10, 11], squeeze-casting [12], laser-melting [13], fraction stir $[14,15]$ and stir cast $[16,17]$. The latter technique, i.e., stir cast, is commonly used to obtain a better uniform distribution of $\mathrm{SiC}$ nanoparticles in the $\mathrm{Al}$ matrix. In this way, the $\mathrm{Al}$ matrix is melted in a furnace and stirred to form a vortex in the presence of inert gas to prevent the oxidation of aluminum. Importantly, $\mathrm{SiC}$ reinforcement particles are added at a predefined rate to the periphery of the vortex. Then, the stirring process is continued until all particles are added, and subsequently, the melt of composites is poured into a mold. It should be noted that after getting the final composites, they may be further subjected to heat treatment or other second processing to improve some properties. The critical process parameters are speed of stir, the time during stir, stir temperature, and the temperature of mold [17-19]. It is reported that some industries are not flexible enough to accept new alloys or to replace the well-known alloys [20,21]. This, in turn, paves the way toward physical as well as chemical enhancement to provide alloys for replacement the conventional one. In this sense, the microstructure, corrosion performance, and electrochemical behavior for the traditional Al-6061 are subjected to comparative study to provide clear insights on the role of the reactive manufacturing process on the corrosion behavior [22]. Machining of Al-6061 alloy using Finite Element Method (FEM) analysis was conducted to evaluate the cutting forces, chip morphology, and temperature [23]. One of the possible enhancement for the studied alloy is to reinforce by chemical enhancement. Accordingly, a study is conducted for the preparation of a scheme for optimization machining force and surface roughness in end milling of Al 6061 reinforced with $\mathrm{SiC}$ [24]. Some reported data explore the different parameters affecting the properties of Al6061/SiC alloy [25-27]. The residual stress distribution and mechanical properties of friction stir welded dissimilar 7075-T6, and 6061-T6 aluminum alloys were a subject of extensive investigation. Results revealed that the ultimate tensile strength increased while the residual stress decreased as the alloy was enforced by nano-silica [28]. The main objective of the current study is to prepare $\mathrm{Al} 6061$ alloy-SiC composites prepared by the stir casting method with different weight percent of $\mathrm{SiC}$ particle (as the reinforcement phase). The effect of different SiC contents on relative density, apparent porosity, and electrical conductivity was studied. Mechanical properties, including microhardness, tensile test, and a group of elastic moduli (using the ultrasonic nondestructive technique) was investigated.

\section{Materials and Methods}

Al alloy-SiC nanocomposites have been prepared by the stir-casting process. The 6061-Al alloy was used as a matrix of composites. The different weight percentages of SiC particles $(0,1,2,3$, and $4 \mathrm{wt} . \%)$ were used in this work as a reinforcement having particle size $80 \mathrm{~nm}$. The $\mathrm{Al}$ alloy matrix was melted at $800{ }^{\circ} \mathrm{C}$, while the $\mathrm{SiC}$ reinforcement particles were heated in a furnace at $300{ }^{\circ} \mathrm{C}$ for $45 \mathrm{~min}$ to remove the moisture from the surface of the particle and after that $\mathrm{SiC}$ particles were added slowly in the center of the vortex. The melt was thoroughly stirred for 10 min to obtain better distribution for $\mathrm{SiC}$ particles. Then, the melt was poured into a preheated iron mold. The physical properties of prepared composites were measured by the Archimedes method, according to ASTM: B962-08. As described in our recent work [29, 30], the microhardness of all investigated samples was measured according to ASTM: B933-09 using $1.96 \mathrm{~N}$ loads under dwell time of $10 \mathrm{~s}$ according to Eq. (2) [31]:

$$
\mathrm{Hv}=1.854 \times \frac{\mathrm{P}}{\mathrm{D}^{2}}
$$


The stress-strain curve was automatically driven during the measurement, and the values of tensile strength, yield strength, and ductility were calculated accordingly. The ultrasonic longitudinal and shear wave velocities (i.e., $\mathrm{V}_{\mathrm{L}}$ and $\mathrm{VS}_{\mathrm{S}}$ ) propagated in the sintered nanocomposites specimen, using the pulse-echo technique MATEC Model MBS8000 DSP (ultrasonic digital signal processing) system. The values of Lame's constants, i.e., $\lambda$ and $\mu$ are obtained from $\mathrm{V}_{\mathrm{L}}$ and $\mathrm{V}_{\mathrm{S}}$ as follows [32]:

$$
\begin{aligned}
& \lambda=\rho\left(V_{L}^{2}-2 V_{S}^{2}\right) \\
& \mu=\rho V_{S}^{2}
\end{aligned}
$$

where $\rho$ is the material bulk density

The values of the elastic moduli; longitudinal modulus $(L)$, shear modulus $(G)$, Young's modulus $(E)$, bulk modulus $(B)$ and Poisson's ratio $(v)$ as calculated from the following equations [33, 34]:

$$
\begin{aligned}
& L=\lambda+2 \mu \\
& G=\mu \\
& E=\mu \frac{3 \lambda+2 \mu}{\lambda+\mu} \\
& B=\lambda+\frac{2}{3} \mu \\
& \nu=\frac{\lambda}{2(\lambda+\mu)}
\end{aligned}
$$

The electrical conductivity $(\sigma)$ of the sintered nanocomposites was measured at $30{ }^{\circ} \mathrm{C}$, using a Keithley 6517B system according to the formula [35].

$$
\sigma=\frac{\mathrm{h}}{\mathrm{RA}}
$$

where $R, h$, and $A$ are the electrical resistance, the thickness of the specimen, and the surface area of the specimen, respectively.

\section{Results and Discussion}

\subsection{Relative density and apparent porosity.}

Fig. 1 shows the effect of nano-SiC contents on bulk density, relative density, and apparent porosity of the AA6061/SiC composites. It can be seen that the relative density increases while apparent porosity of composites increases with the increase in SiC weight percentages, while relative density decreases. The value of the theoretical density of AA6061$0,1,2,3,4$ wt.\% SiC were $2.700,2.704,2.707,2.71$ and $2.713 \mathrm{~g} / \mathrm{cm}^{3}$, respectively, while the value of relative density of the same samples were $98.75,98.22,96.67,94.57$ and $93.41 \mathrm{~g} / \mathrm{cm}^{3}$, respectively. These results may be due to the large difference in density values of the $\mathrm{SiC}$ and $\mathrm{Al}$ alloy matrix. So, the successive increase in $\mathrm{SiC}$ contents leads to a considerable increase in density and reduction in the apparent porosity. Moreover, tensile stresses result from a large difference in coefficient of thermal expansion (CTE) between $\mathrm{Al}$ alloy matrix and SiC reinforcement (CTE of $\mathrm{Al}$ alloy and $\mathrm{SiC}$ are $23.4 \times 10^{-6}$ and $3.8 \times 10^{-6}$, respectively), would normally form defects such as porosity and dislocations around the SiC particles [36]. Furthermore, with increasing $\mathrm{SiC}$ weight percentages, the number of phase boundaries between $\mathrm{Al}$ alloy matrix and $\mathrm{SiC}$ reinforcement increases which consequently, causes an increase in the pore nucleation and noticeable weakness in the wettability at the interfaces between them [37]. Similar interpretation [38] has been reported for the reinforcement of AA356 alloy by zirconia $\left(\mathrm{ZrO}_{2}\right)$, which stated that $\mathrm{ZrO}_{2}$ ceramic directly affected the contacts between it and AA356 
matrix and therefore, closed pores are formed. Subsequently, the relative density of composites decreases with the successive increase of $\mathrm{ZrO}_{2}$ contents.

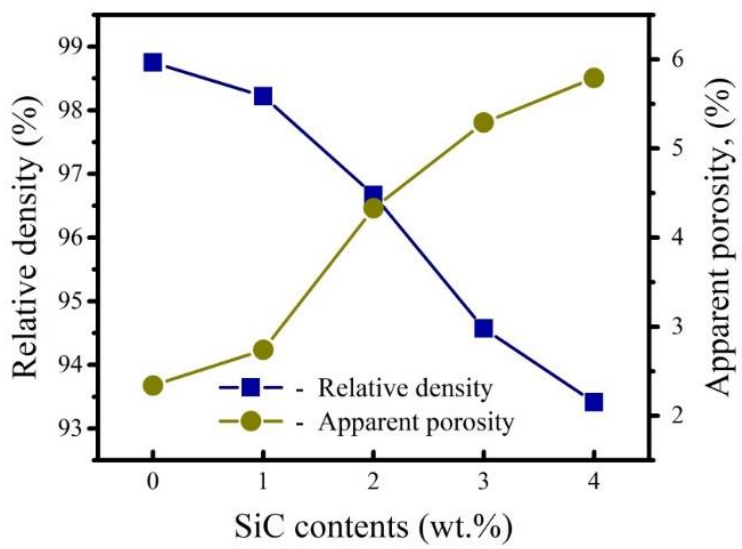

Figure 1. Relative density and apparent porosity of composites samples as a function of SiC contents.

\subsection{Mechanical properties.}

For composites samples containing a soft matrix (Al alloy) and a hard reinforcing phase (SiC particles), evaluating the microhardness data is essential. In this regard, Vickers microhardness (Hv) of the $\mathrm{Al}$ alloy matrix and composites-containing different $\mathrm{SiC}$ contents is illustrated in Fig. 2. It is clear that from the figure that the microhardness of the prepared composites is higher than that of $\mathrm{Al}$ matrix alloy. The ultrasonic velocities (longitudinal $\left(\mathrm{V}_{\mathrm{L}}\right)$ and shear $\left(\mathrm{V}_{\mathrm{S}}\right)$ ) results for $\mathrm{Al}$ alloy- $\mathrm{SiC}$ composites sample are shown in Fig. 3. It appears a gradual increase in ultrasonic velocities from 6521 and $6984 \mathrm{~m} / \mathrm{s}$ to 2951 and $3588 \mathrm{~m} / \mathrm{s}$ for longitudinal and shear velocities respectively when $\mathrm{SiC}$ weight percentages successively increase from 0 to 4 wt. \%.

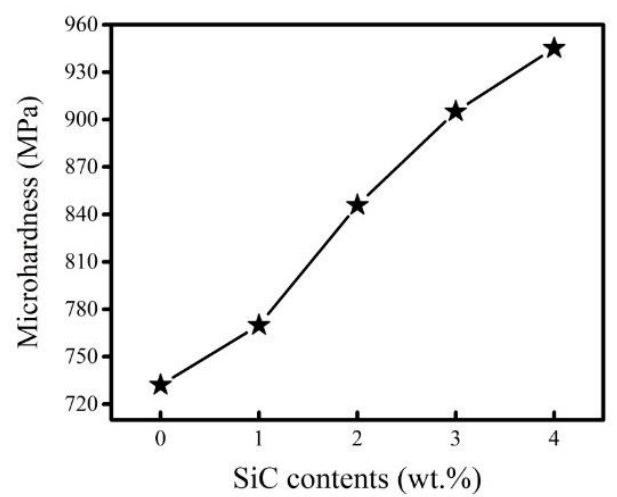

Figure 2. Microhardness of $\mathrm{Al}$ alloy matrix composites at different $\mathrm{SiC}$ contents.

Young's modulus (E), elastic modulus $(\mathrm{L})$, shear modulus $(\mathrm{G})$, bulk modulus $(\mathrm{K})$ and Poisson's ratio $(v)$ of composites in relationship with $\mathrm{SiC}$ contents were tabulated in Table 1, while elastic modulus and passion ratio, as representatives for the whole group, are displayed in Fig. 4. It appears that all values of elastic moduli clearly improved after being reinforced with different contents of SiC particles. For the Al alloy, the elastic modulus and Poisson's ratios are $85.3 \mathrm{GPa}$ and 0.3098 . However, they increase up to $139.5 \mathrm{GPa}$ and 0.3207 when the weight percentage of $\mathrm{SiC}$ increases to $4 \mathrm{wt} . \%$. 


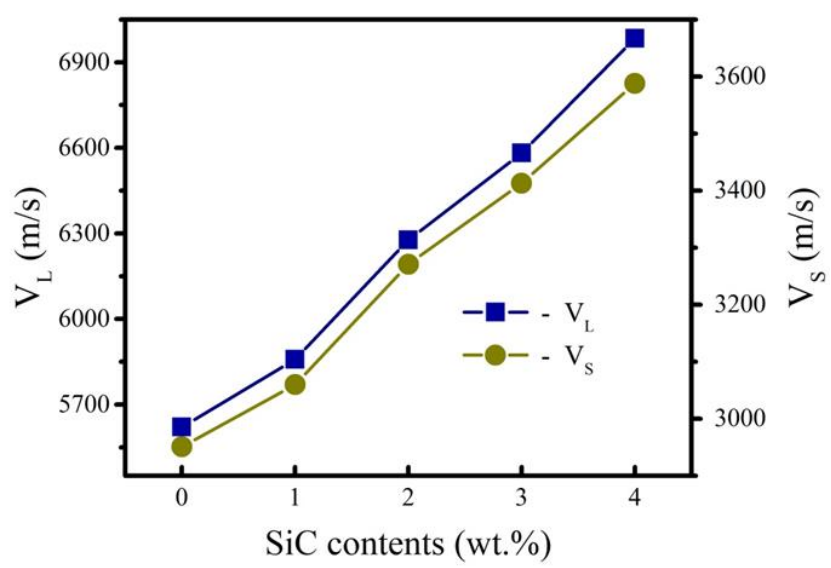

Figure 3. Longitudinal and shear ultrasonic velocities of $\mathrm{Al}$ alloy matrix composites.

Table 1. Young's (E), elastic (L), bulk (B), shear (G), and Poisson's ratio (v) of nanocomposites-containing different weight percentages of $\mathrm{SiC}$.

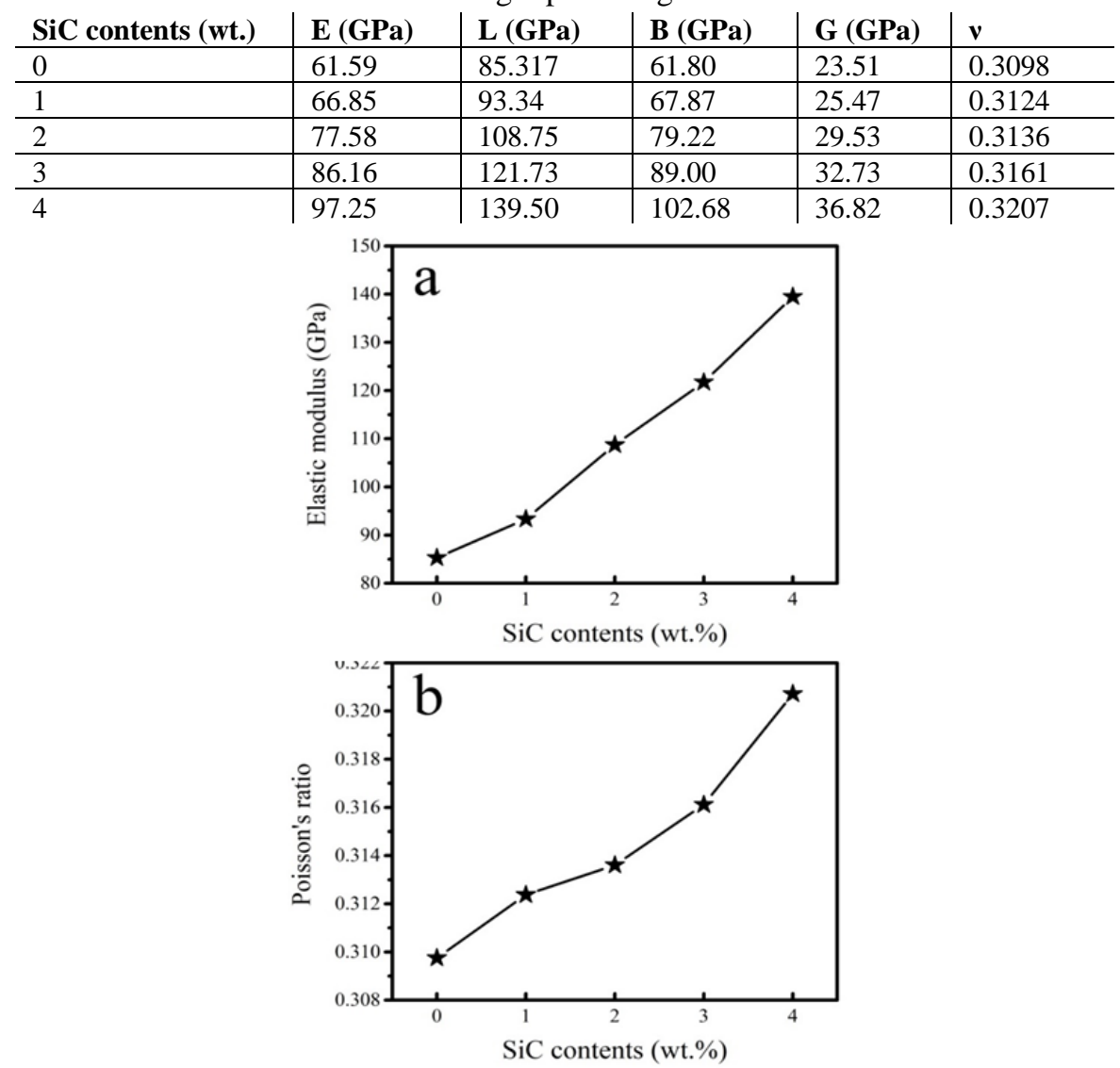

Figure 4. a) Elastic modulus and b) Poisson's ratio of $\mathrm{Al}$ alloy- $0,1,2,3$, and 4 wt.\% SiC composites samples.

Fig. 5 displays the tensile stress-strain curves for $\mathrm{Al}$ alloy and $\mathrm{Al}$ alloy-SiC composites at room temperature. The value of tensile strength, yield strength, and ductility, which is calculated from stress-strain curves as a function of $\mathrm{SiC}$ contents is shown in Fig. 6. It can be observed that the effect of increasing $\mathrm{SiC}$ weight percentages on tensile and yield strength follows the same trend for microhardness and the family of elastic moduli as they increase with increasing $\mathrm{SiC}$ contents, while the ductility exhibits the opposite trend. The value of tensile strength of $\mathrm{Al}$ alloy-0, 1, 2, 3, and 4 wt.\% of $\mathrm{SiC}$ composites were 161.5, 179.6, 199.1, 226.3, and 146.6 MPa, respectively. On the other hand, the ductility of the same samples was 28.4, $26.8,25.9,22.8$, and $20.8 \%$, respectively. 


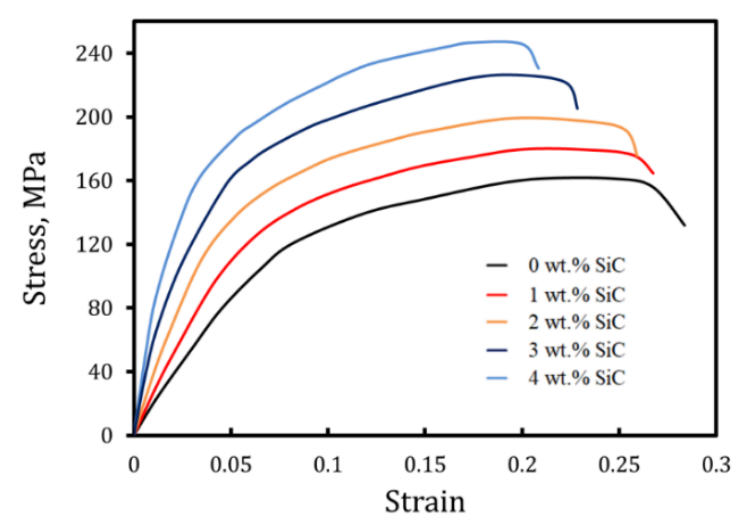

Figure 5. Tensile stress-strain curve of $\mathrm{Al}$ alloy-SiC composite samples.
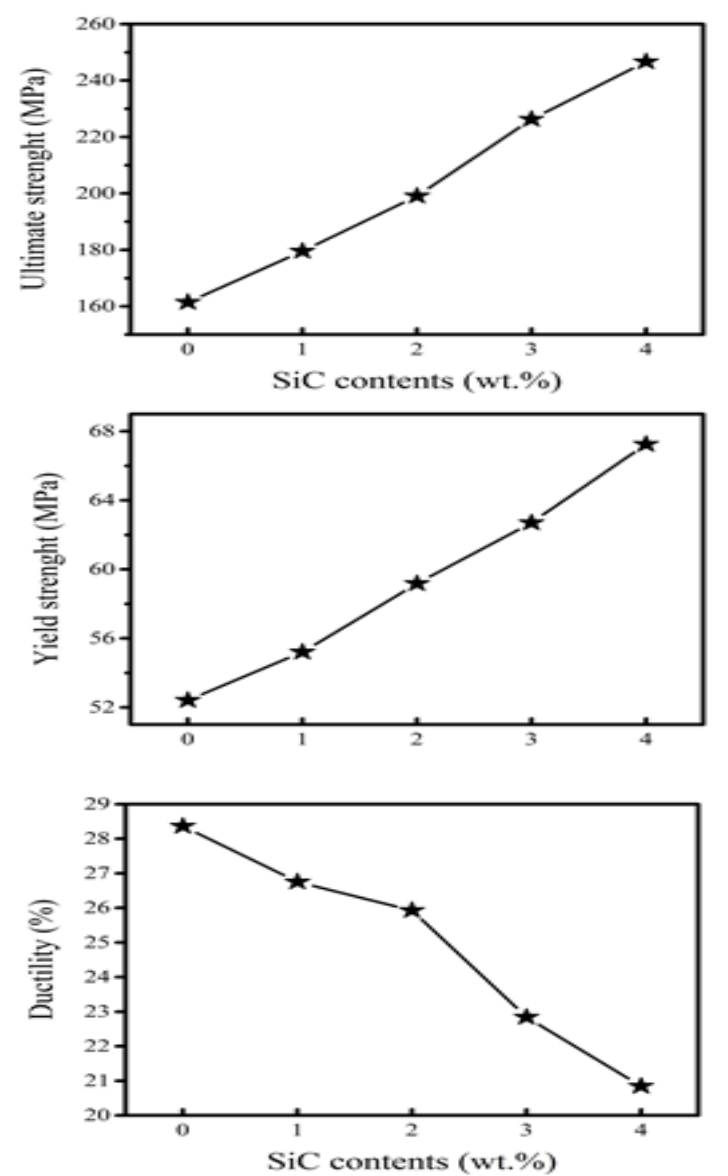

Figure 6. Ultimate strength, yield strength, and ductility of composites samples.

Fig. 7 shows the efficient load transfer ( $\sigma_{\text {load }}$ ) of composites as a function of different volume percentages of $\mathrm{SiC}$ particles can be calculated by Eqn. 10 [39].

$$
\sigma_{\text {load }}=0.5 V \sigma_{Y}
$$

Where $\mathrm{V}$ is a volume fraction of SiC particles, and $\sigma_{\mathrm{Y}}$ is the yield strength. The value of efficient load transfer increases with the increasing of $\mathrm{SiC}$ contents due to that it mainly depends on the increases in yield strength with increases in SiC contents and confirm the good interfacial contact between the matrix and the reinforcement.

Apparent strengthening efficiency (i.e., $\mathrm{R}_{\mathrm{a}}$ ) of composites samples as a function of $\mathrm{SiC}$ weight percentages is shown in Fig. 8. Noteworthy, $\mathrm{R}_{\mathrm{a}}$ can be defined as the ratio of the amount of increase in the yield strength of a composite to that of the Al alloy matrix by the addition of 
$\mathrm{SiC}$ particles [40]. It is noted from this figure that the improvement of $\mathrm{R}_{\mathrm{a}}$ as a result of increasing $\mathrm{SiC}$ contents. The $\mathrm{R}_{\mathrm{a}}$ value can be calculated by eqn. 11 [41]:

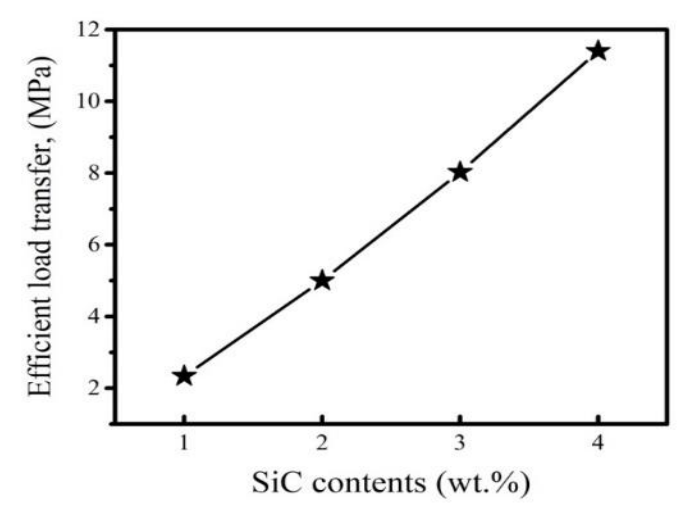

Figure 7. Efficient load transfer $\left(\mathrm{R}_{\mathrm{a}}\right)$ of composites at different $\mathrm{SiC}$ contents.

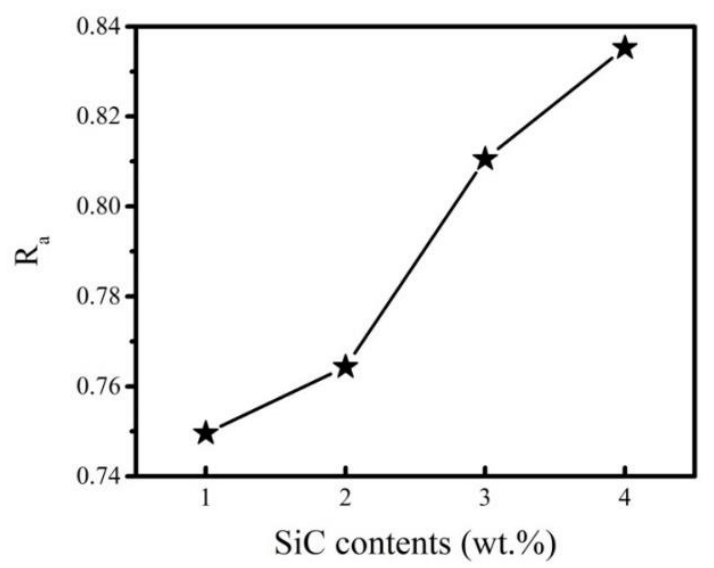

Figure 8. Apparent strengthening efficiency $\left(\mathrm{R}_{\mathrm{a}}\right)$ of composites at different $\mathrm{SiS}$ contents

$$
\mathrm{R}_{\mathrm{a}}=\frac{\sigma_{\mathrm{c}}-\sigma_{\mathrm{m}}}{\mathrm{V} \sigma_{\mathrm{m}}}
$$

where $\sigma_{c}$ is the yield strength of the composite, $\sigma_{\mathrm{m}}$ is the yield strength of the Al alloy matrix, $\mathrm{V}$ is the volume fraction of $\mathrm{SiC}$ particles. It can be found that $\mathrm{R}_{\mathrm{a}}$ of $\mathrm{SiC}$ in the $\mathrm{Al}$ alloy matrix composites is increasing with the increases in $\mathrm{SiC}$ contents.

According to mixtures rule [42], the presence of $\mathrm{SiC}$ reinforcement particles can improve the microhardness of composites as follows:

$$
\mathrm{H}_{\mathrm{C}}=\mathrm{H}_{\mathrm{Al}} \mathrm{F}_{\mathrm{Al}}+\mathrm{H}_{\mathrm{SiC}} \mathrm{F}_{\mathrm{SiC}}
$$

where $\mathrm{Hc}$ represents microhardness of the composite, $\mathrm{H}_{\mathrm{Al}}$ and $\mathrm{H}_{\mathrm{SiC}}$ represent microhardness of the $\mathrm{Al}$ alloy and the $\mathrm{SiC}$ particle, respectively. However, $\mathrm{F}_{\mathrm{Al}}$ and $\mathrm{FSiC}_{\mathrm{SiC}}$ represent the volume fraction of $\mathrm{Al}$ alloy and $\mathrm{SiC}$ particles, respectively. These results can be discussed by knowing that the microhardness of $\mathrm{SiC}$ phase is higher than that of $\mathrm{Al}$ alloy, taking into account that a homogenous distribution of $\mathrm{SiC}$ reinforcement in the $\mathrm{Al}$ matrix has a great role to play in further improvement of microhardness of the prepared composites [37, 43]. It should be noted that the reason behind the noticeable improvements in strength, microhardness, and elastic moduli in the presence of a mismatch in the thermal expansion of SiC particles and $\mathrm{Al}$ alloy, which causes an increase in dislocation density within the matrix. Thus, local stress occurs, which increases the strength of the matrix and the prepared composite. On the other hand, the interaction 
between the dislocations and $\mathrm{SiC}$ particles improves the strength of the composite according to the Orowan mechanism. Because of the existence of dispersed SiC particles in the Al alloy, dislocation loops are formed when dislocations interact with the $\mathrm{SiC}$ particles [39]. Furthermore, Al alloy can be plastically deformed, while the deformation of SiC particles generally remains elastic because it is characterized by higher yield stress. Therefore, the stress inside the particles remains very high. In the process of load transfer between matrix and reinforcement during the tensile test, the boundary is assumed to be strong, and $\mathrm{SiC}$ particles prevent the plastic deformation of the $\mathrm{Al}$ alloy, which improves the strength $[38,44]$.

\subsection{Electrical properties.}

The effect of SiC addition on the electrical conductivity is represented in Fig. 9. The electrical conductivity of the composites exhibited a gradual decrease with respect to $\mathrm{SiC}$ content variation. The electrical conductivity of Al alloy was $2.71 \times 10^{8}$ and with adding $1,2,3$, 4 wt. $\% \mathrm{SiC}$, it decreases to $2.49 \times 10^{8}, 1.99 \times 10^{8}, 1.62 \times 10^{8}, 1.11 \times 10^{8} \mathrm{~S} / \mathrm{m}$, respectively. This decreasing trend in electrical conductivity can be attributed to that the conductivity of SiC reinforcement is low compared to the $\mathrm{Al}$ alloy matrix. Moreover, as the $\mathrm{SiC}$ contents increase, the boundaries between the $\mathrm{Al}$ alloy and $\mathrm{SiC}$ particles and the pores result in the electron movement barriers providing electrical conductivity [45, 46]. Zawrah et al. [37] studied the effect of adding 5, 10, 15 and $20 \mathrm{wt} . \%$ of SiC particles to Al-20 wt.\% Si alloy, and they found a significant decrease in conductivity, namely $88 \%$ of the resulting composite compared to that of $\mathrm{Al}$ alloy. Taha et al. [43] reported that the conductivity of $\mathrm{Al}-4.5 \mathrm{Cu}$ alloy was decreased by $97 \%$ after the addition of 8 wt. $\%$ of $\mathrm{ZrO}_{2}$.

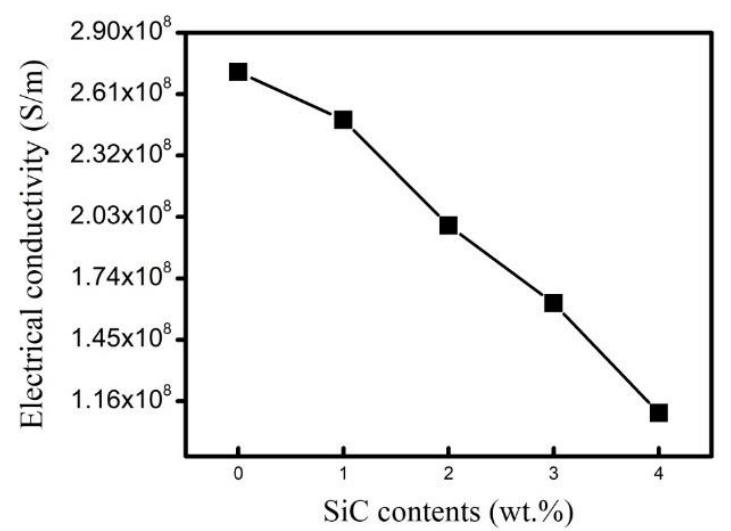

Figure 9. Effect $\mathrm{SiC}$ contents on the electrical conductivity of composites.

\section{Conclusions}

From the obtained results, the following points can be concluded: Al alloy matrix composites having various $\mathrm{SiC}$ contents (i.e., 0, 1, 2, 3, and $4 \mathrm{wt}$.\%) were successfully produced by the stir-casting process; With the increase in $\mathrm{SiC}$ contents, the relative density decreased to $93.41 \%$, and apparent porosity increased up to $5.79 \%$ for the composite containing 4 wt. $\%$ of $\mathrm{SiC}$; Microhardness of the composites samples increased with increased $\mathrm{SiC}$ contents. The measured microhardness value of Al alloy and composite- containing 4 wt. \% SiC was 732.2 and 945.2 MPa, respectively; The ultimate strength, yield strength, and group of elastic moduli increased with increased $\mathrm{SiC}$ weight percentages, while ductility decreased. Apparent strengthening efficiency of Al alloy matrix was dramatically improved, reaching 11.4 for $\mathrm{Al}$ 
alloy-doped with 4 wt. of $\% \mathrm{SiC}$; The electrical conductivity of the composite samples was reduced with increasing $\mathrm{SiC}$ contents.

\section{Funding}

This research received no external funding.

\section{Acknowledgments}

This research has no acknowledgment.

\section{Conflicts of Interest}

The authors declare no conflict of interest.

\section{References}

1. Singh, P.; Dixit, G. Tensile and compressive behaviour of solid glass microspheres reinforced LM13 aluminum alloy based metal matrix composites. IJITEE 2020, 9, 2278-3075, https://doi.org/10.35940/ijitee.c8522.019320.

2. Taha, M.A.; Zawrah, M.F. Fabrication of $\mathrm{Al}_{2} \mathrm{O}_{3}-\mathrm{ZrO}_{2}-\mathrm{Ni}$ composites with improved toughness using nano powders prepared by mechanical alloying. Ceram. Int. 2020, 46, 19519-19529, https://dx.doi.org/10.1016/j.ceramint.2020.05.002.

3. Taha, M.A.; Nassar, A.H.; Zawrah, M.F. In-situ formation of composite having hard outer layer based on aluminum dross reinforced by $\mathrm{SiC}$ and $\mathrm{TiO}_{2}$. Constr. Build Mater. 2020, 248, https://dx.doi.org/10.1016/j.conbuildmat.2020.118638.

4. AbuShanab, W.S.; Moustafa, E.B. Effects of friction stir processing parameters on the wear resistance and mechanical properties of fabricated metal matrix nanocomposites (MMNCs) surface. Mater Res Technol. 2020, 9, 7460-7471, https://doi.org/10.1016/j.jmrt.2020.04.073.

5. Taha, M.A.; Youness, R.A.; Ibrahim, M. Biocompatibility, physico-chemical and mechanical properties of hydroxyapatite-based silicon dioxide nanocomposites for biomedical applications. Ceram Int. 2020, 46, 23599-23610, https://dx.doi.org/10.1016/j.ceramint.2020.06.132.

6. Taha, M.A.; Youness, R.A.; Zawrah, M.F. Phase composition, sinterability and bioactivity of amorphous nano-CaO-SiO ${ }_{2}-\mathrm{CuO}$ powder synthesized by sol-gel technique. Ceram Int. 2020, 46, 24462-24471, https://dx.doi.org/10.1016/j.ceramint.2020.06.231.

7. Youness, R.A.; Taha, M.A.; Ibrahim, M.A. In vitro bioactivity, molecular structure and mechanical properties of zirconia-carbonated hydroxyapatite nanobiocomposites sintered at different temperatures. Mater Chem Phy. 2020, 239, https://dx.doi.org/10.1016/j.matchemphys.2019.122011.

8. Youness, R.A.; Taha, M.A.; El-Kheshen, A.A.; Ibrahim, M. Influence of the addition of carbonated hydroxyapatite and selenium dioxide on mechanical properties and in vitro bioactivity of borosilicate inert glass. Ceram Int. 2018, 44, 20677-20685, https://dx.doi.org/10.1016/j.ceramint.2018.08.061.

9. Rezaei, M.R.; Albooyeh, A.; Shayestefar, M.; Shiraghaei, H. Microstructural and mechanical properties of a novel Al-based hybrid composite reinforced with metallic glass and ceramic particles. Mater Sci Eng. 2020, 786, https://dx.doi.org/10.1016/j.msea.2020.139440.

10. Taha, M.A.; Zawrah, M.F. Effect of nano $\mathrm{ZrO}_{2}$ on strengthening and electrical properties of Cu-matrix nanocomposits prepared by mechanical alloying. Ceram Int. 2017, 43, 12698-12704, https://dx.doi.org/10.1016/j.ceramint.2017.06.153.

11. Zawrah, M.F.; Taha, M.A.; Abo Mostafa, H. In-situ formation of $\mathrm{Al}_{2} \mathrm{O}_{3}$ /Al core-shell from waste material: Production of porous composite improved by graphene. Ceram. Int. 2018, 44, 10693-10699, https://dx.doi.org/10.1016/j.ceramint.2018.03.101.

12. Natrayan, L.; Senthil, K.M. Study on squeeze casting of aluminum matrix composites-A review. In: Advanced Manufacturing and Materials Science. Edition:1, Puplisher: Springer Nature 2018, pp. 75-83, https://dx.doi.org/10.1007/978-3-319-76276-0_8.

13. Li, W.; Liu, J.; Zhou, Y.; Li, S.; Wen, S.; Wei, Q.; Yan, C.; Shi, Y. Effect of laser scanning speed on a Ti45Al-2Cr-5Nb alloy processed by selective laser melting: Microstructure, phase and mechanical properties. Acta Mater. 2017, 136, 90-104, https://dx.doi.org/10.1016/j.scriptamat.2016.02.022.

14. Moustafa, E.B.; Melaibari, A.; Basha, M. Wear and microhardness behaviors of AA7075/SiC-BN hybrid nanocomposite surfaces fabricated by friction stir processing. Ceram. Int. 2020, 46, 16938-16943, https://doi.org/10.1016/j.ceramint.2020.03.274.

15. Moustafa, E.B.; Mosleh, A.O. Effect of (Ti-B) modifier elements and FSP on 5052 aluminum alloy. Alloys Compd. 2020, 823, https://doi.org/10.1016/j.jallcom.2020.153745.

https://biointerfaceresearch.com/ 
16. Sabry, I.; Ghafaar, M.A.; Mourad, A.H.I.; Idrisi, A.H. Stir casted SiC-Gr/Al6061 hybrid composite tribological and mechanical properties. SN Appl Sci. 2020, 2, https://dx.doi.org/10.1007/s42452-020-27134.

17. Ramanathan, A.; Krishnan, P.K.; Muraliraja, R. A review on the production of metal matrix composites through stir casting-Furnace design, properties, challenges, and research opportunities. J. Manuf. Process. 2019, 42, 213-245, https://dx.doi.org/10.1016/j.jmapro.2019.04.017.

18. Krishna, G.S.V.; Subrahmanyam, B.V.; Lakshmi, B. Mechanical characteristics of $\mathrm{Al}_{-} \mathrm{Al}_{2} \mathrm{O}_{3}-\mathrm{SiC}_{\mathrm{C}}$ metal matrix composites made by stir casting technique. Mater Sci Eng. 2019, 653, https://dx.doi.org/10.1088/1757-899x/653/1/012005.

19. Ashok, N.; Shanmughasundaram, P. Effect of particles size on the mechanical properties of SiC-reinforced aluminium 8011 composites. Mater Technol. 2017, 51, 667-672, https://dx.doi.org/10.17222/mit.2016.252.

20. Rafieazad, M.; Mohammadi, M.; Nasiri, A.M. On microstructure and early stage corrosion performance of heat treated direct metal laser sintered AlSi10Mg. Addit Manuf. 2019, 28, 107-119, https://dx.doi.org/10.1016/j.addma.2019.04.023.

21. Rubben, T.; Revilla, R.I.; De Graeve, I. Influence of heat treatments on the corrosion mechanism of additive manufactured AlSi10Mg. Corros Sci. 2019, 147, 406-415, https://dx.doi.org/10.1016/j.corsci.2018.11.038.

22. Torbati-Sarraf, H.; Torbati-Sarraf, S.A.; Chawla, N.; Poursaee, A. A comparative study of corrosion behavior of an additively manufactured Al-6061 RAM2 with extruded Al-6061 T6. Corros Sci. 2020, 174, https://doi.org/10.1016/j.corsci.2020.108838.

23. Parida, A.K.; Rao, P.V.; Ghosh, S. Influence of cutting speed and nose radius in the machining of Al-6061: FEM and experimental validation. Mater Today Pro. 2020, 27, 2569-2573, https://dx.doi.org/10.1016/j.matpr.2019.10.142.

24. Umamaheswarrao, P.; Sankar, B.R.; Nancharaiah, T. Multi objective optimization of process parameters of Al 6061-SiCp metal matrix composite in end milling-hybrid GRA-PCA approach. Mater Today Pro. 2020, 26, 696-700, https://dx.doi.org/10.1016/j.matpr.2019.12.407.

25. Sankar, P.U.; Raju, D.R.; Suman, K.N.S.; Sanker, B.R. Determination of optimal cutting and tool geometry parameters for better surface integrity of hard turned AISI 52100 steel-hybrid GRA-PCA. Adv. Comput. Manuf. 2019, 297-308. https://dx.doi.org/10.1007/978-981-32-9072-3_25.

26. Umamaheswarrao, P.; Raju, D.R.; Suman, K.N.S.; Sankar, B.R., Achieving optimal process parameters during hard turning of AISI 52100 bearing steel using hybrid GRA-PCA. Key Eng Mater. 2019, 818, 87-91, https://dx.doi.org/10.4028/www.scientific.net/KEM.818.87.

27. Umamaheswarrao, P.; Raju, D.R.; Suman, K.N.S.; Sankar, B.R. Hybrid optimal scheme for minimizing machining force and surface roughness in hard turning of AISI 52100 steel. Int J Eng Sci Technol. 2019, 11, https://dx.doi.org/10.4314/ijest.v11i3.3.

28. Jafari, H.; Mansouri, H.; Honarpisheh, M. Investigation of residual stress distribution of dissimilar Al-7075T6 and Al-6061-T6 in the friction stir welding process strengthened with $\mathrm{SiO}_{2}$ nanoparticles. Manuf Process. 2019, 43, 145-153, https://dx.doi.org/10.1016/j.jmapro.2019.05.023.

29. Youness, R.A.; Taha, M.A.; El-Kheshen, A.A.; El-Faramawy, N.; Ibrahim, M. In vitro bioactivity evaluation, antimicrobial behavior and mechanical properties of cerium-containing phosphate glasses. Mater Res Express 2019, 6.

30. Khalil, E.M.A.; Youness, R.A.; Amer, M.S.; Taha, M.A. Mechanical properties, in vitro and in vivo bioactivity assessment of $\mathrm{Na}_{2} \mathrm{O}-\mathrm{CaO}-\mathrm{P}_{2} \mathrm{O}_{5}-\mathrm{B}_{2} \mathrm{O}_{3}-\mathrm{SiO}_{2}$ glass-ceramics. Ceram Int. 2018, 44, 7867-7876, https://dx.doi.org/10.1016/j.ceramint.2018.01.222.

31. Fayad, A.M.; Fathi, A.M.; El-Beih, A.A.; Taha, M.A.; Abdel-Hameed, S. A.M. Correlation between antimicrobial activity and bioactivity of Na-mica and Na-mica/fluorapatite glass and glass-ceramics and their corrosion protection of titanium in simulated body fluid. Mater Eng Perform. 2019, 28, 5661-5673, https://dx.doi.org/10.1007/s11665-019-04296-5.

32. Youness, R.A.; Taha, M.A.; Ibrahim, M. In vitro bioactivity, physical and mechanical properties of carbonated-fluoroapatite during mechanochemical synthesis. Ceram. Int. 2018, 44, 21323-21329, https://dx.doi.org/10.1016/j.ceramint.2018.08.184.

33. Youness, R.A.; Taha, M.A.; Ibrahim, M. Dense alumina-based carbonated fluorapatite nanobiocomposites for dental applications. Mater. Chem. Phy. 2020, https://dx.doi.org/10.1016/j.matchemphys.2020.123264.

34. Ouis, M.A.; Taha, M.A.; El-Bassyouni, G.T.; Azooz, M.A. Thermal, mechanical and electrical properties of lithium phosphate glasses doped with copper oxide. Bull. Mater. Sci. 2019, 42, https://dx.doi.org/10.1007/s12034-019-1897-y.

35. Moustafa, E.B.; Taha, M.A. Preparation of high strength graphene reinforced Cu-based nanocomposites via mechanical alloying method: microstructural, mechanical and electrical properties. Appl Phy A. 2020, 126, https://dx.doi.org/10.1007/s00339-020-3412-0.

36. Cem Okumus, S.; ASLAN, S.; Karslioglu, R.; Gultekin, D.; Akbulut, D. Thermal expansion and thermal conductivity behaviors of Al-Si/SiC/graphite hybrid metal matrix composites (MMCs). Mater Sci. 2012, 18, https://dx.doi.org/10.5755/j01.ms.18.4.3093. 
37. Zawrah, M.F.; Abo Mostafa, H.; Taha, M.A. Effect of SiC content on microstructure, mechanical and electrical properties of sintered Al-20Si-xSiC nanocomposites fabricated by mechanical alloying. Mater Res Express. 2019, 6.

38. Abdizadeh, H.; Baghchesara, M.A. Investigation on mechanical properties and fracture behavior of A356 aluminum alloy based $\mathrm{ZrO}_{2}$ particle reinforced metal-matrix composites. Ceram. Int. 2013, 39, 2045-2050, https://dx.doi.org/10.1016/j.ceramint.2012.08.057.

39. Habibnejad-Korayem, M.; Mahmudi, R.; Poole, W.J. Enhanced properties of Mg-based nano-composites reinforced with $\mathrm{Al}_{2} \mathrm{O}_{3}$ nano-particles. Mater Sci Eng A. 2009 519, 198-203, https://dx.doi.org/10.1016/j.msea.2009.05.001.

40. Cha, S.I.; Kim, K.T.; Arshad, S.N.; Mo, C.B.; Hong, S.H. Extraordinary strengthening effect of carbon nanotubes in metal-matrix nanocomposites processed by molecular-level mixing. Adv. Mater. 2005, 17, 1377-1381. https://dx.doi.org/10.1002/adma.200401933.

41. Chen, B.; Li, S.; Imai, H.; Jia, L.; Umeda, J.; Takahashi, M.; Kondoh, K. Load transfer strengthening in carbon nanotubes reinforced metal matrix composites via in-situ tensile tests. Compos. Sci. Technol. 2015, 113, 1-8, https://dx.doi.org/10.1016/j.compscitech.2015.03.009.

42. Kim, H.S. On the rule of mixtures for the hardness of particle reinforced composites. Mater Sci Eng A. 2000, 289, 30-33, https://doi.org/10.1016/S0921-5093(00)00909-6 .

43. Taha, M.A.; Elkomy, G.M.; Mostafa, H.A.; Gouda, E.S. Effect of $\mathrm{ZrO}_{2}$ contents and ageing times on mechanical and electrical properties of $\mathrm{Al}-4.5 \mathrm{wt} . \% \mathrm{Cu}$ nanocomposites prepared by mechanical alloying. Mater Chem Phy. 2018, 206, 116-123, https://dx.doi.org/10.1016/j.matchemphys.2017.11.058.

44. Zhang, Q.; Zhang, H.; Gu, M.; Jin, Y. Studies on the fracture and flexural strength of Al/Si p composite. Mater. Lett. 2004, 58, 3545-3550, https://dx.doi.org/10.1016/j.matlet.2004.07.006.

45. Srivastave, V.C.; Ojha, S.N. Microstructure and electrical conductivity of Al-SiCp composites produced by spray forming process. Bull Mater Sci. 2005, 28, 125-130, https://doi.org/10.1007/BF02704231.

46. Islak, S.; Kir, D.; Buytoz, S. Effect of sintering temperature on electrical and microstructure properties of hot pressed Cu-TiC composites. Sci Sintering 2014, 46, 15-21, https://dx.doi.org/10.2298/sos1401015i. 